This is an Accepted Manuscript of an article published by Taylor \& Francis in

Pedagogy, Culture and Society on October 2016, available online:

http://www.tandfonline.com/ -

http://dx.doi.org/10.1080/14681366.2016.1252418

\title{
(Semi)Public places, practices and pedagogy
}

\section{Donna Rooney}

Faculty of Arts and Social Sciences, University of Technology Sydney, Sydney, Australia

Donna.Rooney@uts.edu.au

University of Technology Sydney

PO Box 123, Broadway, NSW, Australia 2007

Donna is a lecturer in adult education at the University of Technology Sydney. Her research interests come under the broad area of adult learning in sites other than educational institutions: including workplaces, professional learning, and learning in communities. She draws from a range of conceptual resources.

Keywords: public pedagogy; learning; place; practice; public toilets

Disclosure and acknowledgements: No known or anticipated financial interests or benefits arise from the direct applications of their research. No external funding was involved in this project. The author acknowledges the contributions of colleagues and friends who shared images of toilet texts and pointed her to various sources of related literature. Acknowledgement and thanks too, to Dr Marie Manidis who provided feedback on language concepts drawn on in the paper along with Dr Terry Fitzgerald 
who cast his scrupulous editing eye over the final draft. Finally, I acknowledge and thank the reviewers for their constructive feedback and helpful suggestions.

\begin{abstract}
Rather than being banal and uninteresting, Western women's public toilets may be seen as educational spaces. While prolific in number and usage, they have typically escaped research attention. This paper argues that the common inclusion of toilet texts in these places renders them not only interesting but also worthy of inclusion in accounts of public pedagogies. The paper draws attention to the pedagogical voices that occupy the ostensible privacy of places like toilets. It does so by discussing a collection of toilet texts using the entangled concepts of place, practice and pedagogy. Overall, the paper demonstrates how the texts act as proxy for absent pedagogues who seek to disseminate particular knowledges and/or promote specific cultural practices, and in doing so it repositions women's (semi)public toilets as richly pedagogical.
\end{abstract}

Key words: toilet texts; public toilets; public pedagogy; place; signs

\title{
Introduction
}

The material arrangements of women's toilets in Western societies suggest that toileting is an intensely individual and cloistered practice. The combination of exposed body parts, the 'filth' associated with various excretions (Douglas 2002), as well as the accompanying odours and noises, typically means that the act of toileting and much of its associated cleansing is extremely private business. Stalls and doors provide protection from those who might glimpse and thus be revolted by the filth or by genitalia, or both. In the solitary confines of the stall - hidden from the gaze of others women do what is necessary and then reorganise themselves in order to be 'acceptable' 
enough to re-enter the public domain.

But is that all there is? This paper suggests that far from being hidden from the gaze of others, women are under the scrutiny of a rather eclectic audience which, acting as absent pedagogues, co-opts them into pedagogical relationships. The medium for cooption is the texts or signs innocuously posted on the walls and doors of toilets. These texts have a social purpose: to promote particular knowledges and practices over others. In this way the texts can be understood a pedagogical. They provide instruction in culturally appropriate toileting practices, shape gender, construct race, and influence consumption and environmental practices, as well as instruct on civic responsibilities, security, the law and so forth. This paper investigates almost 200 texts found in toilets, and in doing so positions public toilets as rich sites of learning.

It is commonly accepted that learning happens in places beyond educational institutions. It can be found in all manner of public places (Giroux 2016). Over the last decade or so, the pedagogy of a range of sites has appeared in research literature: from community centres (Rooney 2011), sheds (Golding et al. 2008) and libraries (Cox et al. 2000) to social movements (Ollis 2008) and workplaces (Hager 2011). This paper adds women's toilets to the list. The warrant for such an addition is that the banality of toilets tends to result in them being disregarded in studies concerned with learning. Further still, there is merit in exploring forms of pedagogy in all its manifestations (Giroux in Sandlin, Schultz \& Burdick 2010), particularly when the places involved are prolific amid the sites women occupy as they go about their everyday civic and social lives (Listverse 2009).

Two early caveats are necessary before continuing. The complexities of public/private binaries are evident when considering the toilets in which the texts this paper refers to are located. The toilets are not located in private dwellings, so on the one 
hand they might be considered 'public'. However, the word 'public' as it refers to toilets (as well as with its other usages) is contestable (McKee 2009; Young 2009). When the word is used as an adjective for 'toilets' there is an assumption that anyone can access them and this is not necessarily the case. The wider sites in which the toilets discussed in this paper are located shape who can reasonably access them. For example, they were located within universities, shops, cafes and bars, doctors' offices, and hospitals. This means access is limited by the users' identities as academics, students, customers, patients and so forth. Furthermore, with few exceptions, these toilets where located in Australia, which means that they are typically Western toilets. Further still, within Western culture toilets are typically gender designated. Therefore, given the researcher's gender, the study is limited to Western toilets accessible by women. Hence, rather than being 'public' in a broad sense the toilets referred to here are betwixt public and private in that they are neither located in private dwellings nor necessarily accessible by the broader general public. So, while the simplified word 'toilet' is largely used throughout this paper for convenience, this should be understood as Western women's (semi)public toilets (Young 2009).

A second caveat concerns the toilet texts themselves. While graffiti is common in the sorts of public toilets discussed here, it is not of central concern to this paper. Graffiti, it is true, constitutes an interesting text that is worthy of research interest. Several studies exist where these texts are examined with an eye toward communication patterns (Leong 2014); forms of public address (Iveson 2007); counter messages; youth culture; creative and/or criminal pursuits (Paul 107 2003). What unifies graffiti research is the overall disruptive nature of the texts, and the artist/authors' transgressions (e.g. Paul 107 2003). In contrast, the texts of interest in this paper are those that have some sort of sanctioned presence. Unlike graffiti that can be seen as illegitimate and its 
authors' criminalised (or glorified, depending on who is evaluating), the interest here is in those texts that have been legitimately authored and displayed - and generally sanctioned by the organisation in which the toilet is located. Indeed, this assumption of their authors' power lends weight to the texts' messages.

Like all texts, these toilet texts manifest in a social context that is not simply a stage for action but is implicated in the exchanges between the author and the reader; in this case, between the text and the toilet user, the teacher and the learner. To claim the texts as pedagogical would be difficult without also understanding the places in which they manifest: Western women's (semi)public toilets. Hence, after scanning an interesting array of related literature and providing some methodological detail, the paper presents a discussion of toilet texts utilising three interrelated concepts: place, practice and pedagogy. While presented sequentially in the service of clarity, the concepts are understood as intertwined and mutually constituted. With that said, introducing them sequentially has the benefit of enabling some rhetorical scaffolding that builds to a specific discussion of pedagogy.

First, the concept of place provides a useful starting point to describe the sites where the texts are located. In describing the places of toilet texts, the idea of practices that occur within them emerges, and this leads to the second concept for discussion: practices. In particular, the practices the texts either promote or discourage entwine both place and text. Practised often enough, particular practices come to be associated with place (Seamon 1980) and the texts work to sustain these particular practices over others. This consideration of practices then establishes the groundwork for a specific discussion of pedagogy and by drawing lightly on language scholarship explicit links are made between the texts and how they go about their pedagogical 'work'. In all, consideration of toilet texts in terms of place, practice and pedagogy shifts prosaic 
understandings of toilets and extends notions of public pedagogy (Sandlin, Schultz \& Burdick 2010).

\section{Toilet papers}

There is a surprising number of scholars whose research interests feature toilets in some capacity. Some examples include history (Eveleigh 2006; Newton 2009; Quiltzau 2004), gender (Anthony \& Dufresne 2007; Stead 2009), planning and sustainability (Willets et al. 2010), graffiti (Young 2009), health (Corkill 2012), crime, law, sanitation (George 2008), queering (McKee 2009), toilet practices (Bobel 2010; Quiltzau 2004), as well as toilet texts (Schapper 2012; Young 2009). While some of these studies allude to potential pedagogical practices of toilet texts, few explicitly foreground it. One exception is from health, where Corkill (2012) undertook a time series study to explore the impact of educational toilet posters in staff stalls on clinical practices in an emergency department. While she found positive correlations she also warned that these 'teaching spaces could become over saturated with educational posters' and that staff may become 'immune to the information provided' (Corkill 2012, p. 34). This paper contends that Western women's (semi)public toilets are already 'saturated with educational posters' that take, however, a range of different guises to those described by Corkill (2012).

Among the toilet-focused literature are several fascinating historical accounts of the emergence of toilets in Western societies (Bobel 2010; Crawford 1981; Newton 2009; Quiltzau 2004). Many attribute the development of public toilets to the growth in mobility. Like all histories, there are alternate versions offered, but a common explanation is as follows. As transport around and between cities became more common a parallel requirement also emerged -to accommodate the bodily needs of travellers, especially women. While it might have been somewhat acceptable for men to relieve 
themselves in side streets, concerns about women's modesty demanded a suitable solution. One was found in the building of public/private spaces that would enable women to do what was necessary whilst protecting the broader public from viewing these activities and the women from being viewed. Non-Western toilets have different histories again, and Van der Ryan's (1999) small book on the topic comes well recommended, as does Gregory and James' (2006) book.

A more recent history can be found in the work of Newton (2009), who investigated Australia's attachment to 'the dunny'. The dunny is Australian slang for toilet, and generally means outhouse toilets with metal 'cans'. The dunny-can required regular emptying and so there were also dunny-men[sic] with dunny-carts for this purpose. Dunnies were in use as recently as the 1980s in some suburbs of Sydney, and their legacy can be seen throughout inner Sydney suburbs where narrow laneways run behind rows of terrace houses. This is because toilets, or outhouses, were located at the rear of most properties and the laneways provided access for the sanitation workers to replace full cans with empty ones. In outer suburbs and regional areas such laneways were not so common, thus dunny-men were more visible on the streets. Newton (2009) listened to older Australian's stories of holidaying in rural Australia and noted how their stories included anecdotes about the dunny and/or the dunny-man. In her analysis she draws attention to how the stories were a combination of disgust and laughter.

The dunny continues to amuse (and disgust) in its multiple appearances in popular Australian culture. For example, Slim Newton's (1972) song Redback on the toilet seat earned him a local music award. It tells the story of a man visiting the outhouse only to be bitten by a redback (a very poisonous Australian spider). More recently an Australian comedy film Kenny, about an optimistic plumber who maintained portable toilets, enjoyed considerable success at the box office (Jacobson 2006). 
However, the theme of disgust and laughter is not limited to Australian popular culture. Elsewhere in the Western world toilet humour has also made us laugh - some examples include the 'Mr Hankey, the Christmas Poo' episode of Southpark (Parker 1997), and a Seinfeld episode entitled 'The stall' (Cherones 1994). While these examples provide further evidence of our ability to laugh at toileting practices and associated matters, it is suggested that the laughter also indicates 'unease' (Praeger 2007, p. 14).

Amusement aside, there is also much focus on the gender work of these places. For example, Stead (2009) questions why, given the abundance of euphemisms for toilets, there so few for the urinal (English) or pissoir (French). She imagines the reason to be either because urine is less offensive or because they are solely for male use ( $\mathrm{p}$. 132). Skeggs' (2001) ethnographic work takes readers to toilets in gay and lesbian bars in the United Kingdom. Her focus is to investigate the gender identity work of the female bar goers that occurs in the toilets and illustrate the complexities of constructions of femininity in these spaces. Schapper (2012) provides an analysis of texts found in public toilets in Victoria, Australia, and argues that these texts are unique and rich examples of cultural and gendered practices. She concludes that 'public toilets are sites used to order the disorder of women's bodies and activities' (p. 294).

Taking a different slant on gender, Anthony and Dufresne (2007) write about 'potty parity' in the United States and the inequalities in regard to numbers of, and access to, public toilets for women. One of their examples was of toilets near the Senate chamber in Washington, D.C - with 'Senators Only' on the door (p. 271). This was the default for male toilets, and carried an assumption that senators must all be men. Retrofitted female senators' toilets near the Senate chamber were not added until 1994 Examples of similar 'potty parities' can be found in an original building of the University of Technology Sydney, where there are also retrofitted women's toilets. 
Built in the 1970's as an institute of 'technology', the assumption was that there would be no female students. However, there were assumptions where women would be - the only women's toilets in the engineering faculty were located near the faculty's administration office.

Concerns of inequitable access to toilets in Western countries somewhat diminish in consideration of global access to toilets in other parts of the world. George (2008) points out that over two and a half billion people do not have access to toilets or basic sanitation. The impact of this is the spread of disease, as evidenced by number of hospital beds occupied by people whose illness stems from the lack of basic sanitation, or worse, the number of people that die for want of it. What is also evident in George's and others' work (e.g. Van der Ryan 1999) is the unsustainability of Western toilets given the enormous amounts of water they use to flush away waste.

Finally, a related corpus of literature on bodily practices in toilets can be noted. Notwithstanding the use of public toilets for 'beats" ${ }^{1}$ (McKee 2009; Molotch \& Norén 2010) or as social spaces where women gather for reasons other than toileting, much literature is concerned with the bodily practices and by-products that Western toilets are typically designed for (Crawford 1981; Haslam 2012; Lee 2009; Praeger 2007). A commonality across this literature, with few exceptions (see Bobel 2010), is that the products of these practices are generally taken to be 'filth' (Douglas, 2002). With this understanding, anxieties surround toileting are heightened. Praeger (2007) offers an explanation for this in his description of 'faecal denial', that is, vilification of other people's 'filth' and denial of one's own (p. 56).

\footnotetext{
${ }^{1}$ The term 'beat' is used in Australia to identify places where men who have sex with men meet
} for casual sex. Inner-city public toilets are well represented amongst such beats. 


\section{Methodology?}

When complying with the practice of writing journal articles, it is generally appropriate to say something of methodology. Hence I start with a confession - while the later stages of this research assumed a methodology-of-sorts, its beginnings several years ago were far from rigorous. The genesis of this paper came from a small sticker on a toilet roll dispenser in a toilet cubicle in my university workplace: 'Mount toilet roll dispenser with bottom parallel to toilet seat ... use a minimum of three screws' (note: italics are used throughout the paper to indicate actual toilet texts). The unintended meaning of these words continued (and continues) to amuse me - although having now read about the relationship between filth and laughter, I am no longer quite so amused.

After noticing this sticker I also started noticing other texts in other toilets and, with my phone camera, began capturing images of texts in the toilets I visited as part of my own requirements. While most were in Sydney, Australia, conference and leisure travel enabled me to photograph some signage in overseas public toilets as well. As I collected more of these images I realised that they would, at some stage, become the data for an article such as this. As I became more convinced that I would 'do something' with them I became more rigorous in 'data collection'. Like Schapper (2012), I avoided photography when other women were in attendance. I began to keep structured notes on the location of toilets where texts were found, as well as their location within the toilet itself. Over a period of three years I photographed an assortment of toilet texts, which I keep in a folder on my laptop. As I began mentioning the growing portfolio of pictures to colleagues and friends, they too began sending pictures of texts they had photographed.

At the time of writing there are around 200 electronic images in the folder. Some of these are of signs located outside toilets or at the entry of toilet blocks - their purpose 
largely to assist potential users find the location of gender-appropriate facility. While there are many fascinating variations on the typical skirt- and non-skirt-wearing stick figures, there is no discussion of these here. Rather, my focus here is on the texts found inside the toilet cubicles and in vestibule areas of toilets.

I then undertook a thematic analysis of these toilet texts. I was interested first in the broad field or topic the sign addressed, and second in the sanctioned and unsanctioned practices, including the consequences of compliance (or deviance). Where applicable, the justifications or warrants for these directives and the assumptions of the reader supposed by the signs were also of interest. Finally, I also explored any euphemisms used to mention 'unmentionables' and the meanings implied by any pictographs used in the texts.

\section{Place}

By way of presenting the analysis, I start by introducing the toilet texts in the interrelated terms of place, practice and pedagogy. I begin with the geographical concept of place because not only does understanding place offer a way to understand the world, but it also nicely illustrates the entanglement between the texts and the knowledges and practices they promote. Cultural geographers emphasise that places derive meaning from the relationship of their locales and habitual practices with the particular things that constitute them (Cresswell 2004). Indeed, Creswell, drawing on Agnew, suggests that places have location (coordinates), locale (referring to materiality), and have 'a sense of place' (meanings) (p. 7). This three-part understanding of place provides a helpful discussion starter for introducing the toilet texts, as well as for illustrating how place is implicated in the texts' messages. 


\section{Location of (semi)public toilets}

A first facet of place was that each toilet visited had a 'location'. For example, while the toilets visited may not necessarily be on the official Australian National Public Toilet Map (Department of Health 2016), it would still be possible to add their geographical coordinates. Perhaps more correctly, the toilets visited were places within places. That is, they were situated within other places such as universities, pubs, restaurants, doctors' offices, shops and other non-residential sites. These situating places of toilets shaped the types of people who accessed them just as much as the gendered signs that included and excluded those who might enter (These toilets are for the convenience of library users).

The location of toilets and assumptions about the women that are likely to use them also influence the content of toilet texts. For instance, texts found in pubs included warnings about alcohol consumption (What will you think in the morning?), and when the location included gaming machines the dangers of gambling were often presented (Your chances of winning are less than one in a million) - whereas texts found in shops warned users about the consequences of stealing (Shoplifters will be prosecuted). In places where food was available there were also texts for employees (Employees must wash their hands before returning to work) - although the latter may also speak to patrons. Already understandings of place are seen as implicated in the texts.

Furthermore, where the text's main purpose was to advertise, the location of toilets also appeared to influence the nature of the products promoted. It was clear that the authors of toilet texts in the form of advertisements had made assumptions about the types of women that would be reading them: that is, using the toilets. For instance, advertisements for condoms and/or dental dams and/or tampons were common in nightclubs - assuming young women were likely to be sexually active and/or menstruating. However, in Returned Services League clubs, which older people are 
more likely to frequent, advertisements for incontinence or aged-pension products were common.

A further example that links location and toilet texts was seen in gambling establishments. The Australian gambling industry has made concentrated (and somewhat successful) efforts to lure East Asian gamblers (Filali, Middleton \& Calixto 2012) - yet while the Asian dollar may be highly desirable in these places, the general thrust of toilet texts in a Sydney casino suggests that the toileting practices of Asian gamblers themselves are not so desirable (No squatting - see below for more on this).

When considered together, these texts and their location begin to illustrate the careful consideration given by texts' authors - as if they were actually there observing the toilet users. The texts are not targeted to a random or universal woman, but to very particular groups of women with very particular bodily, sexual, and cultural circumstances.

\section{Materiality of (semi)public toilets}

A second facet of place is that the toilets I visited have 'locale', that is, materiality. Places are, after all, 'material things' (Creswell, 2004, p. 7). For example, Western toilets have basic material features such as walls, roofs and doors. Many of the toilets visited had stalls with locking devices which enabled women to use them without being seen by others. Of course, they also had an actual toilet bowl and most were fitted with a seat. Some also had a vestibule area, with a mirror, and almost all had at least one sink (see Schapper 2012 for an extensive description of materiality of toilets). The combination of material features of toilets produces them as particular kinds of places. For example, stalls and doors sustain the intensity private nature of toileting and the location of vestibule areas between the stalls and the exit door works to sustain sanctioned hygiene practices. 
An important aspect of materiality of these places was the assortment of texts in them. These were located on walls, behind doors, over sinks, on mirrors and, in vestibule areas. While a few were handwritten/drawn, the vast majority were printed. Where written language was included, most were in English - although a few examples were written in other scripts. The choice of script was often related to location (e.g. Asian script in casinos). There were also texts with minimal use of script but instead made use of pictographs to convey messages. Many texts were laminated, which suggests some permanency. Others consisted of 'stickers' adhered to equipment such as like toilet paper dispensers, hand dryers, or refuse bins. Some were more temporarily fixed to the wall, whereas others were framed under glass and more permanently fixed to the walls/doors with screws. The number of texts in the toilets varied, but as I became attuned to looking for toilet texts it was rare to not find at least one example. Incidentally, a toilet on a train in the UK had the largest number of texts (over 20).

\section{The meaning of (semi)public toilets}

As already mentioned, the materiality of toilets, including the texts in them, helps construct the meaning of them as places. For some geographers place is space endowed with meaning. Hence, a third facet of place is their 'relationship to humans and the human capacity to produce and consume meaning' (Creswell, 2004, p. 7). Toilets can be places of fear, that is, fear associated with the 'criminals' who might loiter in them. Toilet texts instruct users on how to avoid becoming victims (Keep your belongings safe), along with information about surveillance (Regular security patrols are for your safety; Staff have instructions to report illegal behaviour).

More commonly, toilets carry meanings of filth and shame. Notwithstanding the possibility of toilet stalls being used for activities involving more than one person (e.g. sex, drug use), the act of voiding is an intensely private business that is supported by the 
materiality (stalls, doors, etc.) in women's toilets. The by-products of toileting are presumed to be filthy (Campkin \& Cox 2007). This meaning of toilets as places of filth was evident in the toilet texts where an obligation to 'Clean up after oneself' was apparent - in some cases further direction about how to do this was stipulated (Use toilet brush provided; There is a toilet brush provided in each cubicle for this reason). Further still, motives for removing evidence of 'filth' were provided (in the interest of other users). In all, many toilet texts contributed not only to the meaning of toilets as being places of abject filth, but also to a disavowal of toileting practices and bodily functions.

This disavowal is evident in the many euphemisms used when general talk turns to toilets (Stead 2009). While users may indeed rest, wash, powder, or become comfortable, these are not the prime purpose of restrooms, washrooms, powder rooms, or comfort stations, or for that matter the facilities, bathroom, conveniences, ladies', women's, little girls' room, or the many other euphemisms used. However, the use of euphemisms is not limited to describing the places alone. They are commonly found in the toilet texts themselves where the texts' purpose is to provide instructions around what can and cannot be flushed. Examples include girly products, plastic elephants, along with the more common, sanitary items. Two of these might reasonably be assumed to mean tampons or pads used by menstruating women (the reference to plastic elephants bewilders). Other toilet texts remind users not to offend others by leaving behind indications of their toileting practice. Meanwhile, the stall itself maintains the fantasy of privacy and the illusion of propriety (Close the door; To ensure your privacy please lock the door). What is evident here is the filth or dirt associated with toilets and the lengths these texts go to reorder 'matter[s] out of place' (Douglas 2002, p. 36). 
I am by no means alone in noticing the disavowal of toileting (Campkin \& Cox 2007; Crawford 1981; Praeger 2007; Stead 2009; Ussher 2006). Despite the texts that speak to the by-products of women's toileting, it is filth associated with the Other that appears to be of most concern (Hygienic toilet seat covers provided for your protection). Along with Praeger (2007), Campkin and Cox (2007) point to how filth is implicated in the constructions of the Other, in particular suggesting that others' 'habits and practices have frequently been labelled as unhygienic and used to justify denigration and the interference by dominant authorities in the most intimate areas of life' (p. 6). As will be illustrated soon, some of the more disturbing toilet texts perpetuate these ideas. However, other others were not always vilified - in some cases it was because of others that particular practices are called for (For the comfort of others). While some toilet texts speak to heightened anxieties, with reminders about how individuals can avoid catching disease (Be clean), in other texts the purpose of handwashing is less about the individual and more about spreading disease (In the interest of public safety...).

\section{Place and practices}

What has already been hinted about is how place and practices are mutually constituted; places invite practices, and the persistent carrying out of particular practices over time helps create places and their meanings. For example, the materiality of toilets sustains the bodily practices they are initially designed for. Stalls or cubicles ensure that these are carried out in seclusion, thus preserving and perpetuating meanings. However, should a user be unaware of 'acceptable' practices, well-placed toilet texts can offer her instruction (Lock the door).

The toilet texts work to sustain acceptable toileting practices: Flush after use; Turn off taps; Wash your hands; Use soap; Dry hands; Clean up after yourself, and, 
Dispose of refuse. These imperatives make clear what practices are demanded of users. In addition to acceptable practices, unacceptable practices are named or implied in texts, for example, Don't flush while seated and Do not flush [variously named matter] down the toilet. It several instances the texts went to great lengths to instruct users on appropriate toileting practices (No squatting)!

The vestibule areas of women's toilets invite different types of practices. Unlike practices typically carried out by women 'alone' in the stall, practices in the vestibule areas are more open to being observed by other women (Schapper 2012). The common inclusion of a mirror in these areas invites a woman to apply or touch-up her make-up, adjust her clothing and 're-order herself' (Schapper 2012) before re-entering the wider public domain. Meanwhile, a text on the mirror is intended to catch her eye (Take your belongings with you).

\section{Place, practices and pedagogies}

So far, this paper has framed the discussion of Western women's (semi)public toilet texts in terms of place and practice. These texts, and the practices they promote, are entwined with the place and its meanings. While the notion of learning has been implied in the discussion hitherto, this section makes explicit the association of place and practice with pedagogy, as manifest in the toilet texts. It begins with identification of common 'content' of the texts before moving on to an illustration of how the texts work pedagogically.

\section{Content}

Aside from the advertising of various products discussed earlier, the content of the majority of toilet texts was health related, with comprehensive instructions about the importance of washing and drying hands frequently photographed. While there were 
several variations of Wash your hands texts, a commonality was the use of imperatives: Wet [your hands], [then] soap [them] and so forth.

A second content area was the environment. Examples here include texts that informed toilet users about: how many paper towels to reasonably take (two, if you wanted to know); what septic systems can tolerate (and what not); and water source (Toilets use recycled water). There were also several texts that provided information and instructions for the use and disposal of toilet paper:

- Toilet paper shrinks. Other paper expands in pipes. Only use toilet paper provided.

- Please understand you cannot flush a whole roll of toilet paper down the toilet. If you must use the whole roll, can you please flush it down in small amounts or dispose of your soiled paper in the waste bin provided.

Further examples of environmental content of texts included the implications of not turning off taps; and where/how to dispose of waste (other than faeces, urine, blood and vomit). It is in the later example where euphemisms proliferate. While feminine sanitary products and foreign objects where common, some not so common were girly products, and the plastic elephants mentioned earlier.

Another general content area included instructional texts that largely inducted users in an array of toilet practices related to operating toilet technologies, for example, Close the door; Use a bin; as well as how to mount toilet roll dispensers (... use a minimum of three screws) or refill them (Open here). The increase of automation (autoflush toilets, auto-opening bins, auto-taps and doors, automatic soap dispensers and the like) has inspired further instructional texts concerned with teaching users how to operate them (Wave hand across sensor; If paper towels empty please use air dryers on opposite wall). 
Yet another interesting area of induction is that of culturally appropriate ways to use the actual toilet. These most often took the form of pictographs with limited written language. The general thrust of these texts was to instruct users to sit on the toilet rather than squat on it or on the floor. In the most deplorable example I found, a naked woman engages in inappropriate (squatting) behaviour in red-crossed drawings - whereas a woman toileting appropriately is modestly dressed. This not only conveys messages of sanctioned practice, but also what is thought of the non-compliant deviant.

This insistence with sitting is curious given Australia's dynamic multicultural mix. Squatting toilets are common in non-Western countries (where many Australians originate) and so it is little wonder there is some confusion when faced with sitting toilets. A case for the perpetuation of an ethnocentric view of toileting practices might be further supported when considering a general absence of squatting toilet facilities in Australia. Despite a great proportion of Australians originating in countries where squatting is normal, there are no compliance standards for the installation of squatting toilets in Australian homes. This omission not only rejects squatting toilets, but also renders them illegal and those who practice squatting as deviant even 'in the most intimate areas of life' (Campkin \& Cox 2007, p. 6). At the time of writing there is public debate about the Australian Tax Office's decision to install squatting toilets in its main office (Acharya 2016; Ho 2016).

\section{How the texts work}

As should be apparent by now, the discussion of toilet texts throughout this paper has illustrated how they seek to influence women's consumption and environmental behaviours; affirm or change their toileting practices; instruct in technologies' usages; promote civic responsibilities; and construct gender and cultural practices. They do not simply offer up innocent information, but deliberately promote particular knowledges 
and regulate particular practices. In this way they can be considered pedagogical. To further understand the texts as pedagogical it is helpful to consider how their language works to achieve their pedagogical 'duties'. This is done below by borrowing lightly from language scholars to examine a list of toilet text messages:

- Wrappers go in the bin.

- The number of germs on your fingertips doubles after using the toilet.

- Our toilets are checked for cleanliness on a regular basis.

- Sanitary bins are for the disposal of feminine hygiene products only.

- Toilet paper goes in the toilet.

What is common across these examples is their use of propositions. In language scholarship a proposition is

something that can be argued about - something that can be affirmed or denied, and also doubted, contradicted, insisted on, accepted with reservation, qualified, tempered, regretted and so on. (Halliday 1994, p. 70)

The function of a proposition is to disseminate information/facts. Wrappers go in the bin - do they? For the reader (i.e. toilet user) the available responses are to agree or not (Halliday 1994, p. 70). Like the liberal pedagogue, these texts present 'truths' to learners who are expected to accept them as given. To not accept these truths would be to question (the absent author's) authority.

The toilet texts, like teachers, use language to convey privileged knowledges. In the physical absence of the author, the texts act as a proxy to carry out the pedagogical duties. However, pedagogues not only promote particular knowledges, they also use language to influence people's behaviour (Eggins 1994; Halliday 1994). Many of the examples provided throughout this paper fit this category. A second list illustrates this point more explicitly, noting a different form of language use: 
- Please press for 5 seconds.

- Wrap tampons and pads before placing in the bin

- Do not use for disposal for soiled toilet paper, hand towels, cigarette butts, disposable nappies etc.

- Check your belongings before leaving.

- Please put girlie products in paper and plastic and then in the bin

- Do not put foreign objects in the toilet bowl.

Unlike the first list of statements, these later ones do not convey a truth but rather seek to instruct women in some aspect of toileting practice. The available responses to these are not to agree or not, but to comply or not. In some cases the texts proposed what might be done should there be non-compliance (Please do not put our staff in the difficult position of being obliged to call the police because of your behaviour). Like the behaviourist teacher who seeks to bring about some desired behaviour (Merriam, Caffarella \& Baumgartner 2007), these 'proposals' (Halliday 1994, p. 71), are intent on moulding the behaviour of learners. Evident in these texts are the 'covert attempt[s of the authors] to get people to do things' - '[a] faceless expression of power' (Eggins 1994, p. 195). Interestingly, not only were these the most common among the toilet texts, it was also usual for texts to include 'proposal' clauses in the form of sequential instructions, for example, in the use of disposable toilet seat covers: Please read the instructions (1) Pull out this length (2) Tear here ONLY (sic) (3) Spread open over seat - flap in bowl (4) Self-disposing when you finish. Kitsch also tempered some messages: Don't bother with the hover (1) Take some toilet paper (2) Spray liquid onto the toilet paper (3) Wipe the seat and discard.

These texts clearly seek to influence behaviour, and the sanctioned behaviours 
are further upheld by the (arguably) authorless status of most texts. On the rare occasion where an author was implied, there was no doubt as to their authority (e.g. Management; Library Manager; Human Services; Centre Management, Department of Health). 'Faceless expression of power' indeed!

\section{Concluding discussion}

The investigation of toilet texts presented here shows the variety of ways they instruct users in a vast range of matters - from health, safety, security, and technology use; to civic duty, consumerism, and gender, ethnic and cultural induction. It not only shows how toilet users' beliefs and behaviours are under scrutiny, but also how they are intentionally opened up to being manipulated by the pedagogic voices of the toilet texts' absent authors. Health professionals, business owners, managers, company representatives, among others, interrupt these places where women might imagine themselves to be alone. The proliferation of texts in (semi)public toilets alerts us to the gaze of multiple authors, whose texts seek to regulate, sanction and outlaw practices, thus troubling the illusion of toileting being the intensely private business that it is generally believed to be.

Such texts induct users of toilets into sanctioned ways of being and doing. The texts justify the practices they advocate in a variety of ways, with many of them subtly hinting at consequences of acceptance or non-acceptance. Directives are evident in most texts, although humour, rhyme or kitsch can temper some. Further still, euphemisms are employed to refer to the 'unmentionables' - thus reinforcing meanings of filth and abhorrence for this most natural of human practices.

Rather than being banal and uninteresting places, (semi)public toilets are pedagogical places. They are prolific in number yet have typically escaped research 
attention - in particular research attention concerned with learning. Corkill's (2012)

apprehension about the possibility of 'oversaturation' of 'educational posters' in toilets

(p. 34) is a reality, and these seemingly innocuous toilet texts render these places

worthy of inclusion in accounts of public pedagogies. The presence of toilet texts is a

reminder of the multitude of pedagogical voices that occupy the ostensible privacy of

(semi)public places, and this discussion has illustrated how Western women's

(semi)public toilets are already richly pedagogical.

\section{References}

Acharya, Mosiqi. 2016. "Australian Tax Office introduces squat toilets to cater to 'diverse' workforce." SBS: Herald Sun Accessed August 22, 2016. http://www.sbs.com.au/yourlanguage/hindi/en/article/2016/08/09/australiantaxation-office-introduces-squat-toilets-cater-diverse-workforce

Anthony, K., and M. Dufresne. 2007. "Potty parity in perspective: gender and family issues in planning and designing public restrooms." Journal of Planning Literature 21 (3):267-294.

Bobel, C. 2010. New blood: third-wave feminism and the polotics of menstruation.

Campkin, B., and Rosie Cox. 2007. Dirt: new geographies of cleanliness and contamination. London: Tauris \& Co Ltd.

Cherones, T. 1994. The stall. In Seinfeld (Season 5, Episode 12). United States of America.

Corkill, D. 2012. "Testing the effects of educational toilet posters: a novel way of reducing haemolysis of blood samples within ED." Australasian Emergency Nursing Journal 15:31-36.

Cox, Eva, K. Swinbourne, Chris Pip, and Suzanne Laing. 2000. A safe place to go: libraries and social capital. Sydney: Public Library Branch of The State Library of New South Wales.

Crawford, P. 1981. "Attitudes to menstruation in seventeenth-century England." Past \& Present 91 (May):47-73.

Cresswell, Tim. 2004. Place: a short introduction. 2nd ed. Maldon, MA, USA: Blackwell Publishing. Original edition, 2004. Reprint, 2nd.

Department of Health. 2016. National Public Toilet Map. Accessed August 25, 2016. https://toiletmap.gov.au/

Douglas, Mary. 2002. Purity and danger: an analysis of concepts of pollution and taboo. London: Routledge. Original edition, 1966.

Eggins, S. 1994. An introduction to systemic functional linguistics. London: Pinter.

Eveleigh, D. 2006. Bogs, baths and basins: the story of domestic sanitation. Stroud, England: Sutton.

Filali, F., K. Middleton, and J. Calixto. 2012. "Betting on Asia". In Insight. Australia: SBS. Accessed August 1, 2016. www.sbs.com.au/ondemand/video/11854403793/insight-betting-on-asia

George, R. 2008. The big necessity: the unmentionable world of human waste and why 
it matters. New York, NY: Metropolitan Books.

Giroux, H. 2016. "Cultural studies and public pedagogy”. In Encyclopedia of

Educational Philosophy and Theory, edited by Michael Peters. Singapore: Springer. doi: 10.1007/978-981-287-532-7_301-1

Golding, B., H. Kimberley, A. Foley, and M. Brown. 2008. "Houses and sheds in Australia: an exploration of the genesis and growth of neighbourhood houses and men's sheds in community settings." Australian Journal of Adult Learning 48 (2):237-262.

Gregory, Morna E., and Sian James. 2006. Toilets of the world. London \& New York: Merrell.

Hager, P. 2011. Historical tracing of the development of theory in the field of workplace learning. In The SAGE handbook of workplace learning, edited by M.

Malloch, L. Cairns, K. Evans and B. O'Connor. Sage.

Halliday, M. 1994. An introduction to functional grammar. Second ed. London: Edward Arnold.

Haslam, N. 2012. Psychology in the bathroom. London: Palgrave Macmillan.

Ho, Vincent. 2016. "What's the best way to go to the toilet - squatting or sitting?". The Conversation Accessed August 16, 2016. http://theconversation.com/whatsthe-best-way-to-go-to-the-toilet-squatting-or-sitting-63991.

Iveson, K. 2007. "Making a name: writing graffiti in Sydney." In Publics and the city, 112-147. Oxford: Blackwell.

Jacobson, C. 2006. Kenny. Australia: Xenon Pictures.

Lee, J. 2009. "Bodies at menarche: stories of shame, concealment, and sexual maturation." Sex Roles 60 (9-10):615-627.

Leong, Pamela. 2014. American graffiti: deconstructing gendered communication patterns in bathroom stalls. Gender, Place and Culture: A journal of feminist geography. doi: 10.1080/0966369X.2014.991705.

Listverse. 2009. "15 fascinating facts about toilets." [Internet]. Listverse Accessed October 30, 2015. http://listverse.com/2009/06/15/15-fascinating-facts-abouttoilets/

McKee, A. 2009. "Putting the 'public' back into 'public toilets'." Continuum: Journal of Media \& Cultural Studies 11 (3):85-100.

Merriam, S., R. Caffarella, and L. Baumgartner. 2007. "Traditional learning theories." In Learning in adulthood, 275-297. San Francisco, CA: Jossey-Bass.

Molotch, Harvey Luskin, and Laura Norén. 2010. Toilet public restrooms and the politics of sharing. New York: New York University Press.

Newton, J. 2009. "Dunnies and Australian culture: looking backward and forward to explicate community memory." Journal of Australian Studies 31 (91):81-91.

Newton, S. 1972. Redback on the toilet seat. Tamworth: Hadley Records and Yeldah Music.

Ollis, Tracey. 2008. "The 'accidental activist': learning, embodiment and action." Australian Journal of Adult Learning 48 (2):316-335.

Parker, Trey. 1997. Mr Hankey, the Christmas Poo. In SouthPark (Season 1, Episode 10), edited by T. Parker and M. Stone. United States of America.

Paul 107. 2003. All-city: the book about taking space. Toronto: ECW Press.

Praeger, D. 2007. Poop culture: how America is shaped by its grossest national product. Los Angeles, CA: Feral House.

Quiltzau, M. 2004. "Changing ideas in bodily cleanliness." 6th International Summer Academy of Technology Studies. Urban Infrastructure in Transition: what can we learn from history?, Deutscglandsberg, Austria, July 11-17 2004. 
Rooney, D. 2011. "Centres 'down under': mapping Australia's neighbourhood centres." Australian Journal of Adult Learning 51 (2):203-225.

Sandlin, J., B. Schultz, and J. Burdick, eds. 2010. Handbook of public pedagogy: education and learning beyond schooling. New York: Routledge.

Schapper, J. 2012. "The writing is on the wall: the text(ure) of women's toilets in Australia." Gender, Place and Culture 19 (4):494-517.

Seamon, D. 1980. "Body-subject, time-space routines, and place-ballets." In The human experience of space and place, edited by A. Buttimer and D. Seaman. New York: St Martin's Press.

Skeggs, B. 2001. "The toilet paper: femininity, class and mis-recognition." Women's Studies International Forum 24 (3/4):295-307.

Stead, N. 2009. "Avoidance: on some euphemisms for the 'smallest room'." In Ladies and gents: public toilets and gender, edited by O. Gershenson and B. Penner, 126-132. Philadelphia PA: Temple University Press.

Ussher, J. 2006. Managing the monstrous feminine: regulating the reproductive body. East Sussex: Routledge.

Van der Ryan, S. 1999. The toilet papers: recycling waste and conserving water. 2nd ed. White River Junction, VT: Ecological Design Press.

Willets, J., N. Carrard, M. Retamal, D. Nguyen, M. Paddon, D. Do Xuan Thuy, T Nguyen Hieu Trung, and C. Mitchell. 2010. Selecting sanitation options: a case study of South Can Tho. Sydney: Institute of Sustainable Futures, University of Technology, Sydney.

Young, J. 2009. "Restroom politics: voices in the stalls." Lethbridge Undergraduate Research Journal 4 (2):1-10. 